\title{
Sucrose consumption alters steroid and dopamine signalling in the female rat brain
}

\author{
Daniel J Tobiansky ${ }^{1,2, \dagger}$, George V Kachkovski ${ }^{1}$, Reilly T Enos ${ }^{3}$, Kim L Schmidt ${ }^{1}$, E Angela Murphy ${ }^{3}$ and Kiran K Soma ${ }^{1,2,4}$ \\ 1Department of Psychology, The University of British Columbia, Vancouver, British Columbia, Canada \\ 2Djavad Mowafaghian Centre for Brain Health, The University of British Columbia, Vancouver, British Columbia, Canada \\ 3Department of Pathology, Microbiology, and Immunology, School of Medicine, University of South Carolina, Columbia, South Carolina, USA \\ ${ }^{4}$ Department of Zoology, The University of British Columbia, Vancouver, British Columbia, Canada
}

Correspondence should be addressed to K K Soma: ksoma@psych.ubc.ca

${ }^{\dagger}$ (D J Tobiansky is now at Department of Ecology and Evolutionary Biology, Brown University, Providence, Rhode Island, USA)

\begin{abstract}
Sucrose consumption is associated with type 2 diabetes, cardiovascular disease, and cognitive deficits. Sucrose intake during pregnancy might have particularly prominent effects on metabolic, endocrine, and neural physiology. It remains unclear how consumption of sucrose affects parous females, especially in brain circuits that mediate food consumption and reward processing. Here, we examine whether a human-relevant level of sucrose before, during, and after pregnancy (17-18 weeks total) influences metabolic and neuroendocrine physiology in female rats. Females were fed either a control diet or a macronutrient-matched, isocaloric sucrose diet (25\% of kcal from sucrose). Metabolically, sucrose impairs glucose tolerance, increases liver lipids, and increases a marker of adipose inflammation, but has no effect on body weight or overall visceral adiposity. Sucrose also decreases corticosterone levels in serum but not in the brain. Sucrose increases progesterone levels in serum and in the brain and increases the brain:serum ratio of progesterone in the mesocorticolimbic system and hypothalamus. These data suggest a dysregulation of systemic and local steroid signalling. Moreover, sucrose decreases tyrosine hydroxylase $(\mathrm{TH})$, a catecholamine-synthetic enzyme, in the medial prefrontal cortex. Finally, sucrose consumption alters the expression pattern of FOSB, a marker of phasic dopamine signalling, in the nucleus accumbens. Overall, chronic consumption of sucrose at a human-relevant level alters metabolism, steroid levels, and brain dopamine signalling in a female rat model.
\end{abstract}

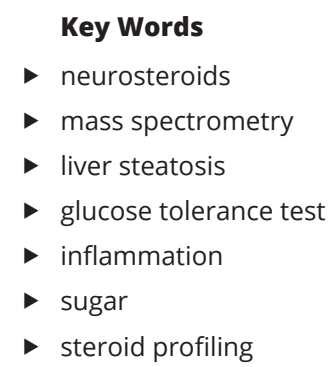

Journal of Endocrinology (2020) 245, 231-246

\section{Introduction}

Sucrose (table sugar) is abundant in the Western diet (Welsh et al. 2011, Newens \& Walton 2016), and consumption of sucrose and other added sugars is three to five times higher $(15-25 \%$ of $\mathrm{kcal})$ than the recommended amount (5\% of kcal; World Health Organization 2015) in the USA and other countries (Welsh et al. 2011). Excess sugar consumption is associated with type 2 diabetes, cardiovascular disease, non-alcoholic fatty liver disease (NAFLD), and certain cancers (Brown et al. 2008, Bray 2010, Tappy \& Lê 2010, Friberg et al. 2011). Clinical and pre-clinical studies demonstrate that sucrose intake disrupts metabolic physiology, such as insulin insensitivity and hepatic steatosis (see Johnson et al. 2009 for review). 
In contrast to these well-known metabolic effects, little is known about how chronic sucrose consumption alters behaviour and the brain (Rada et al. 2005, Reichelt et al. 2016). Chronic sugar intake in rodents impairs shortterm memory (Buyukata et al. 2018), spatial memory (Beilharz et al. 2016, Buyukata et al. 2018), and goaldirected behaviour (Sharpe et al. 2016). The underlying neural mechanisms are not clear but might include changes to the mesocorticolimbic system, a circuit comprised of dopamine (DA) synthesizing neurons in the ventral tegmental area (VTA) and DA-sensitive neurons in the nucleus accumbens (NAc), medial prefrontal cortex (mPFC), hippocampus (HPC), and other areas (Ikemoto 2007). This critical circuit regulates motivation, reward seeking, and executive functions (Floresco et al. 2008, Floresco 2013, Tobiansky et al. 2018a). Repeated sugar consumption affects DA release in the NAc (Rada et al. 2005, Avena et al. 2008) and DA receptors in the NAc (Sharpe et al. 2016). However, many rodent studies only examined males and far less is known about effects on females.

The mesocorticolimbic system and other neural circuits, as well as metabolism and immune function, are profoundly affected by steroid hormones. In particular, androgens and oestrogens modulate DA signalling in the mesocorticolimbic system (Mermelstein \& Becker 1995, Tobiansky et al. 2016). Glucocorticoids also affect DA-dependent feeding behaviour (la Fleur 2006) and mobilize glucose (Kuo et al. 2015). Importantly, sugar intake affects steroid signalling. For example, in young men, sugar-sweetened beverage consumption is negatively associated with circulating testosterone levels (Chen et al. 2018). In rodents, consumption of sucrose or fructose, one of the monosaccharides that comprise sucrose, affects circulating corticosterone levels (Bursać et al. 2013, 2014) and decreases glucocorticoid receptors in the brain (Maniam et al. 2015). Steroidogenic enzymes in the brain are also altered by early-life fructose exposure (Mizuno et al. 2017). Thus, sugar consumption may influence steroid synthesis in the periphery and in the brain, which affect the function of steroid-sensitive neural circuits.

The current study examines whether sucrose consumption affects metabolism, steroids, and neurochemistry in female rat dams. Female rats were fed a diet that contained a human-relevant level of sucrose (i.e. similar to sucrose intake of many people in the USA and other developed countries (25\% of kcal); Welsh et al. 2011, Ruff et al. 2013). Pregnancy and parturition involve major changes in metabolism, steroid hormones, and DA signalling, and thus it is of interest to examine the effects of sucrose intake during this time period.
We examined glucose regulation, hepatic lipogenesis, adipose inflammation, serum and brain steroid levels, and markers of DA synthesis and signalling in the mesocorticolimbic system. Tyrosine hydroxylase (TH) was examined as a marker of DA synthesis, and FOSB was examined as a marker of phasic DA signalling, which is implicated in reward-seeking behaviours in rodent models (Muschamp et al. 2012). This integrative approach allowed us to examine the widespread effects of chronic, humanrelevant sucrose consumption on multiple physiological systems in females.

\section{Materials and methods}

\section{Animals and diets}

Adult female Long-Evans rats (postnatal day 60-70, 232-286 g; $n=20$; Charles River Laboratories) were pairhoused in a temperature-controlled vivarium $\left(22^{\circ} \mathrm{C} ; 40\right.$ to $50 \%$ relative humidity) on a $12 \mathrm{~h}$ light: $12 \mathrm{~h}$ darkness cycle (lights on at 07:00 h). Rats were given ad libitum access to a standard rat chow (Rat Diet 5012; LabDiet, Land O'Lakes Inc., St. Louis, MO, USA) for 1 week after arrival. Rats were given ad libitum access to standard tap water throughout the experiment.

During this week, subjects were gradually introduced to either a control diet (catalogue \#: D12450k; Research Diets, Inc., New Brunswick, NJ, USA) or a custom diet containing sucrose (Research Diets Inc.; Table 1). Importantly, both diets were isocaloric and matched with respect to ingredients and macronutrient composition ( 10\% kcal from fat, 20\% $\mathrm{kcal}$ from protein, and $\sim 70 \% \mathrm{kcal}$ from carbohydrates). In the sucrose diet, $25 \% \mathrm{kcal}$ came from sucrose and $45 \%$ from corn-starch, whereas, in the control diet, all carbohydrate calories came from corn-starch. Females were fed these diets for 10 weeks before mating (Fig. 1). Body mass and food consumption were recorded two times/week. Food consumption and body mass were not measured after mating to avoid disturbance during pregnancy and lactation.

For mating, each female was paired with a different adult male Long-Evans rat (postnatal day 80-90; $n=20$ ). One male and one female were paired together until the female became pregnant. Once pregnant, the males were removed from the cage. After parturition, the dams remained on their respective diet. If dams had a litter size of $>8$, then offspring were culled to eight pups. Dams were then left undisturbed until weaning of pups (25 days). In total, seven control females and nine sucrose 
Table 1 Composition of the control diet and sucrose diet from Research Diets. The sucrose diet with 25\% kcal from sucrose is a custom diet. The macronutrient compositions are matched and the diets are isocaloric ( $3.8 \mathrm{kcal} / \mathrm{g}$ ). Bold indicates difference in diet sucrose content.

\begin{tabular}{|c|c|c|c|c|}
\hline \multirow[b]{2}{*}{ Macronutrient } & \multicolumn{2}{|c|}{ Control diet } & \multicolumn{2}{|c|}{ Sucrose diet } \\
\hline & $\mathrm{g}(\%)$ & kcal (\%) & $\mathrm{g}(\%)$ & kcal (\%) \\
\hline Protein & 19 & 20 & 19 & 20 \\
\hline Carbohydrate & 67 & 70 & 67 & 70 \\
\hline Fat & 4 & 10 & 4 & 10 \\
\hline Total & & 100 & & 100 \\
\hline $\mathrm{kcal} / \mathrm{gm}$ & 3.8 & & 3.8 & \\
\hline Ingredient & g & kcal & g & kcal \\
\hline Casein & 200 & 800 & 200 & 800 \\
\hline L-Cystine & 3 & 12 & 3 & 12 \\
\hline Corn starch & 700 & 2800 & 450 & 1800 \\
\hline Sucrose & 0 & 0 & 250 & 1000 \\
\hline Cellulose, BW200 & 50 & 0 & 50 & 0 \\
\hline Soybean oil & 25 & 225 & 25 & 225 \\
\hline Lard & 20 & 180 & 20 & 180 \\
\hline $\begin{array}{l}\text { Mineral mix } \\
\text { S10026 }\end{array}$ & 10 & 0 & 10 & 0 \\
\hline $\begin{array}{l}\text { Dicalcium } \\
\text { phosphate }\end{array}$ & 13 & 0 & 13 & 0 \\
\hline $\begin{array}{l}\text { Calcium } \\
\text { carbonate }\end{array}$ & 5.5 & 0 & 5.5 & 0 \\
\hline $\begin{array}{l}\text { Potassium } \\
\text { citrate }\end{array}$ & 16.5 & 0 & 16.5 & 0 \\
\hline $\begin{array}{l}\text { Vitamin mix } \\
\text { V10001 }\end{array}$ & 10 & 40 & 10 & 40 \\
\hline $\begin{array}{l}\text { Choline } \\
\text { bitartrate }\end{array}$ & 2 & 0 & 2 & 0 \\
\hline Total & 1055.05 & 4057 & 1055.05 & 4057 \\
\hline
\end{tabular}

females were successfully impregnated and gave birth to a litter of $\geq 4$ pups. The offspring of these dams will be described separately. All procedures were approved by the University of British Columbia Committee on Animal Care and were in accordance with the guidelines of the Canadian Council on Animal Care.

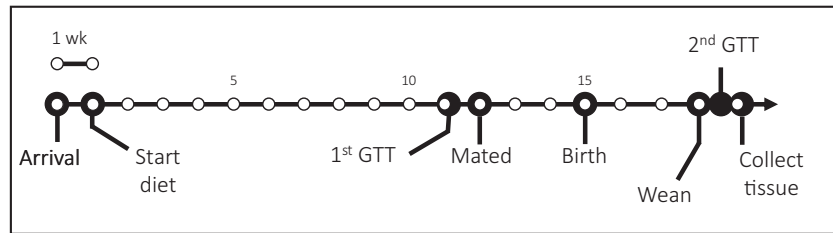

\section{Figure 1}

Study timeline. 'Start diet' is the point at which the females were taken off the standard lab chow and placed on their respective diet for the remainder of the study. The females were given two glucose tolerance tests (GTT): at week 11-12 and week 18-19 after the start of their respective diet. Females were paired with males at week 13 and, on average, gave birth at week 16 . The pups were weaned at approximately week 18 . Females were killed and tissue was collected at approximately week 19.

\section{Glucose tolerance test (GTT)}

A GTT was performed on the females 1 week prior to mating and 3-4 days after weaning of her pups. First, the female was transferred to a clean cage in a procedure room. The subject was fasted for $5 \mathrm{~h}$ (food was removed $1 \mathrm{~h}$ after lights on; 08:00 h), after which a blood sample was collected from the saphenous vein to measure fasting insulin and glucose. Blood glucose was measured using a handheld glucometer (Contour, Bayer AG; Leverkusen, Germany). Sixty minutes later, a second baseline glucose sample was collected via tail puncture. Next, $1.5 \mathrm{~g} / \mathrm{kg}$ glucose was administered i.p. by a 50\% (w/v) glucose solution. Blood glucose levels were measured 15, 30, 60, 90 , and 120 min post-injection via tail puncture.

\section{Insulin ELISA}

After a 5-h fast, blood samples were collected in heparinized haematocrit tubes from a saphenous vein puncture. Blood was transferred to microcentrifuge tube and centrifuged at $4000 \boldsymbol{g}$ for $10 \mathrm{~min}$ at $4^{\circ} \mathrm{C}$. Plasma was stored at $-80^{\circ} \mathrm{C}$ until analysis. Plasma insulin concentrations were performed according to the manufacturer's instructions using a rat insulin ELISA kit (Mercodia Inc., Uppsala, Sweden).

\section{Tissue collection}

Females were killed 3-4 days after the second GTT between 10:00 and 12:00 h (3 to $5 \mathrm{~h}$ after lights on). Food and water were available ad libitum on the day of killing. Subjects were rapidly and deeply anesthetized using isoflurane, weighed, and killed by rapid decapitation. Trunk blood was collected and immediately stored on wet ice until tissue collection was completed. The time between moving the cage and trunk blood collection was $<3 \mathrm{~min}$, to minimize the effects of stress on steroid levels (Taves et al. 2011).

The brain was then extracted and bisected along the midsagittal plane. One hemisphere was flash frozen on powdered dry ice and stored at $-80^{\circ} \mathrm{C}$ for steroid analyses. The other hemisphere was immersion-fixed in $4 \%(\mathrm{w} / \mathrm{v})$ formaldehyde for $4 \mathrm{~h}$ at $4^{\circ} \mathrm{C}$, transferred to a $30 \%$ sucrose solution for 3-4 days at $4^{\circ} \mathrm{C}$, flash frozen on dry ice, and stored at $-80^{\circ} \mathrm{C}$ for immunohistochemistry. After collection of the brain, the liver was weighed. A portion (300-500 mg) of the liver was fixed in $4 \%(\mathrm{w} / \mathrm{v})$ formaldehyde for $1 \mathrm{~h}$ at RT and then stored in 70\% EtOH for histological analysis. The remainder of the liver $(\sim 3 \mathrm{~g})$ was flash frozen on dry ice and stored at $-80^{\circ} \mathrm{C}$ for total 
lipid and triglyceride analyses. Gonadal adipose tissue was weighed, flash frozen on dry ice, and stored at $-80^{\circ} \mathrm{C}$ for mRNA analyses. Finally, the mesentery adipose depot was weighed, and the retroperitoneal and perirenal adipose depots were weighed together. Blood samples were centrifuged (3000 $\boldsymbol{g}$ for $5 \mathrm{~min}$ ), and serum was stored at $-80^{\circ} \mathrm{C}$ for steroid analyses.

\section{Hepatic lipid quantification}

Lipids were isolated from the liver utilizing a modified Folch extraction method and were quantified gravimetrically, as previously described (Enos et al. 2014, 2015, 2016).

\section{Hepatic histology and qualification of pathology}

Formaldehyde-fixed livers were embedded in paraffin blocks and sectioned. Livers were stained with haematoxylin and eosin. Histological examination of the liver specimens was performed by a trained pathologist blind to the treatment groups for the presence of NAFLD according to the scoring system designed by the Pathology Committee of the NASH Clinical Research Network, which addresses the full spectrum of lesions of NAFLD (Kleiner et al. 2005).

\section{Real-time quantitative polymerase chain reaction}

Total RNA was isolated from gonadal adipose tissue using a RNeasy Lipid Tissue Mini Kit (Qiagen) and quantified using a Nanodrop (Thermo Scientific). All samples had 260/280 and 260/230 ratios >1.8. cDNA was synthesized using the High-Capacity cDNA Reverse Transcription Kit with an RNAse inhibitor (Applied Biosystems). Quantitative RT-PCR (Applied Biosystems

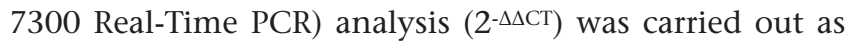
per the manufacturer's instructions (Applied Biosystems) using TaqMan Gene Expression Assays for Emr1 (EMR1; Rn01527631_m1), Tnfa (TNF- $\alpha$; Rn99999017_m1), and Il1b (IL-1 $\beta ;$ Rn00580432_m1) with 18S rRNA as the reference gene. Emr1 is a marker for macrophages in the adipose tissue, and Tnfa and $I l 1 b$ are proinflammatory cytokines. Diet did not influence reference gene (18S) expression in any of the analyses ( $P>0.68$ in all cases).

\section{Brain microdissection and steroid extraction}

Fresh-frozen brain cryosectioning (at $300 \mu \mathrm{m}$ ) and microdissection for steroid analysis are described in detail elsewhere (Tobiansky et al. 2018b). The Palkovits punch technique was employed using an Integra Miltex biopsy punch (1 mm diameter; Fisher Scientific) to microdissect the mPFC (infralimbic/prelimbic border), NAc (shell/ core border), medial VTA, medial preoptic area/medial hypothalamus (POA/HYP), dorsal HPC, and ventral HPC. Wet weight of tissue per punch is $0.245 \mathrm{mg}$ (Taves et al. 2011) and, depending on the region, 5 to 15 punches were collected. Punch locations were confirmed following cresyl violet counterstain (Supplementary Fig. 1, see section on supplementary materials given at the end of this article).

The steroid extraction protocol has been described in detail (Mohr et al. 2019). Briefly, $1 \mathrm{~mL}$ of HPLC-grade acetonitrile and $50 \mu \mathrm{L}$ of $50 \%$ methanol containing deuterated internal standards (corticosterone- $\mathrm{d}_{8}$, dehydroepiandrosterone(DHEA)- $\mathrm{d}_{6}, 17 \beta$-oestradiol( $\left.\mathrm{E}_{2}\right)-\mathrm{d}_{4}$, progesterone- $\mathrm{d}_{9}$, pregnenolone- $\mathrm{d}_{4}$, and testosterone- $\mathrm{d}_{5}$; $\mathrm{C} / \mathrm{D} / \mathrm{N}$ Isotopes Inc., Pointe-Claire, QC, Canada) were added, to correct for matrix effects and sample losses (Tobiansky et al. 2018b). Certified reference standards were used to create calibration curves for a panel of eight steroids (androstenedione, corticosterone, DHEA, $5 \alpha$-dihydrotestosterone (DHT), $\mathrm{E}_{2}$, pregnenolone, progesterone, and testosterone). Blanks, standards, and quality controls were processed with samples.

\section{Liquid chromatography tandem mass spectrometry}

Samples were analysed as previously described (Tobiansky et al. 2018b) with minor modifications. Briefly, samples were injected into a Nexera X2 UHPLC system (Shimadzu Corp., Kyoto, Japan), passed through a KrudKatcher ULTRA HPLC In-Line Filter (Phenomenex, Torrance, CA, USA) and a Poroshell $120 \mathrm{HPH}$ C18 guard column (2.1 mm; Agilent), and separated on a Poroshell $120 \mathrm{HPH} \mathrm{C18}$ column $\left(2.1 \times 50 \mathrm{~mm} ; 2.7 \mu \mathrm{m}\right.$; at $40^{\circ} \mathrm{C}$; Agilent $)$ using 0.1 $\mathrm{mM}$ ammonium fluoride in MilliQ water as mobile phase A and HPLC-grade methanol as mobile phase B (MPB). The flow rate was $0.4 \mathrm{~mL} / \mathrm{min}$. As soon as the samples were loaded, MPB was kept at $10 \%$ for $0.5 \mathrm{~min}$, then gradually increased to $42 \% \mathrm{MPB}$ over $3.4 \mathrm{~min}$ where it remained for another $5.4 \mathrm{~min}$. At $9.4 \mathrm{~min}$, the gradient was increased to $60 \% \mathrm{MPB}$ and gradually increased to $70 \%$ over $1 \mathrm{~min}$ where it remained for another $2.4 \mathrm{~min}$. Finally, the column was washed at $98 \%$ MPB for $1 \mathrm{~min}$. The MPB was then returned to starting conditions for $1.3 \mathrm{~min}$. The injection needle was rinsed before and after each sample injection with $100 \%$ isopropanol. Total run time was $14.9 \mathrm{~min}$. https://joe.bioscientifica.com

https://doi.org/10.1530/JOE-19-0386 (c) 2020 Society for Endocrinology Published by Bioscientifica Ltd.
Printed in Great Britain 
Steroids were analysed with scheduled multiple reaction monitoring (sMRM) with two MRM transitions for each steroid and one sMRM transition for each internal standard. A Sciex 6500 Qtrap triple quadrupole tandem mass spectrometer (Sciex LLC, Framingham, MA, USA) was used to quantify steroid concentrations. Androstenedione, corticosterone, DHEA, DHT, pregnenolone, progesterone, and testosterone were ionized using positive electrospray ionization mode, while $\mathrm{E}_{2}$ was ionized using negative electrospray ionization mode. Progesterone in the dorsal and ventral HPC had low recovery $(<60 \%)$ and evidence of high matrix effects, so progesterone levels in these two regions were excluded from analyses. All water blanks were non-detectable for all steroids of interest. All quality controls were within $10 \%$ of expected values. Assay linearity, accuracy, precision, and matrix effects have been reported previously (Tobiansky et al. 2018b).

\section{Immunohistochemistry and quantification for TH and FOSB}

Fixed brain samples were cryosectioned at $40 \mu \mathrm{m}$ and collected in five series and stored in cryoprotectant at $-20^{\circ} \mathrm{C}$ until immunostaining. A complete series was utilized for each protein of interest, and all subjects were processed together. The immunostaining protocol for TH ((1:1000); clone LNC1, mouse MAB; Millipore; Cat\# MAB318) is described previously (Heimovics et al. 2012, Tomm et al. 2018). Briefly, free-floating sections were incubated in $0.5 \% \mathrm{H}_{2} \mathrm{O}_{2}$ for $30 \mathrm{~min}$ at room temperature (RT), followed by an incubation in blocking solution ( $2 \%$ normal goat serum (NGS) in PBS) for $2 \mathrm{~h}$ at RT. The tissue was then incubated in the blocking solution with the anti-TH antibody for $24 \mathrm{~h}$ at RT. Thereafter, sections were incubated in secondary antibody ((1:2000); BiotinSP-conjugated AffiniPure Goat anti-mouse IgG; Jackson ImmunoResearch Laboratories; Cat\# 115-065-116) in blocking solution for $16 \mathrm{~h}$ at RT. Next, sections were placed in an avidin-biotin complex ((1:2000); VectaStain ABC Kit; Vector Laboratories) for $1 \mathrm{~h}$ at RT. Finally, a chromogenic reaction (20 $\mathrm{min}$ at RT) was performed using Vector Labs Peroxidase Substrate Kit as per the manufacturer's instructions (Vector Laboratories; Cat\# SK-4100). The reaction was terminated by several washes. All incubations were followed by washes $(5 \times 5 \mathrm{~min})$. All washes were with $0.1 \%$ Triton-X 100 in PBS (PBS-T) and all solutions (except the blocking solution) were made with TBS with $0.1 \%$ Triton-X 100 (TBS-T).

The immunostaining protocol for FOSB follows the protocol for cFos immunostaining in Tobiansky et al. (2013) with slight modifications. All washes and solutions were in PBS-T with 0.3\% Triton-X 100. All incubations and washes occurred at RT. Sections were washed in between each incubation step, but were washed once for $1 \mathrm{~min}$ and three times for $5 \mathrm{~min}$. The blocking solution was 3\% NGS in PBS-T. Incubation in the rabbit monoclonal anti-FOSB primary antibody (CST FosB (5G4) Rabbit MAB \#2251; (1:1000); previously used in Zhang et al. 2014) was for $12 \mathrm{~h}$. Tissue was then incubated in a biotinylated secondary antibody (Biotin-SP AffiniPure Donkey Anti-Rabbit IgG; Jackson ImmunoResearch Laboratories; cat \#: 711-065152) in the protein block solution for $3 \mathrm{~h}$. Incubation in the avidin-biotin complex was done at a concentration of 1:500 for $1 \mathrm{~h}$ at RT. Finally, the chromogenic reaction was performed as previously described, but was only allowed to develop for $14 \mathrm{~min}$.

Photomicrographs of TH-ir and FOSB-ir were captured in regions of the mesocorticolimbic system. We captured one rostral image, one central image, and one caudal image of the medial OFC (MOFC; anterior-posterior from bregma (AP): 4.68 to 4.20), lateral OFC (LOFC; bregma +4.68 to +3.00 ), prelimbic mPFC (PrL; bregma +4.20 to +2.76 ), and infralimbic mPFC (IL; bregma +3.72 to +2.76 ). Photomicrographs were also taken in the NAc shell (NAcS; bregma +2.76 to +1.20 ), NAc core (NAcC; bregma +2.52 to +1.28$)$, and the parabrachial pigmented nucleus of the VTA (bregma -5.04 to -6.12; Paxinos \& Watson 2007).

Slides were coded so that the researcher was blind to the group. TH-ir images were captured using a Nikon Digital Sight DS-U1 camera connected to a Nikon Eclipse 90i microscope (10× objective; resolution $2560 \times 1920$; Nikon). FOSB-ir images were captured using an Olympus CX41 microscope (10× objective; Olympus Corporation). Damaged sections were excluded from analysis. Following image acquisition, a region of interest (ROI) was identified for each image, cropped, and converted into 8 bit using Fiji/ImageJ (Schindelin et al. 2012). ROI areas for TH-ir and FOSB-ir were all $44.94 \mathrm{~mm}^{2}$.

For TH-ir quantification, ROIs were processed to produce a mean greyscale value for each image, ranging from 1 (black) to 256 (white). Thus, each ROI had one value (1-256) that denoted the mean greyscale of the pixels. To analyse difference in TH staining, mean greyscale values of the ROIs were compared across groups, similar to previous studies (Mosedale et al. 1996, Matkowskyj et al. 2000). We also validated this method by comparing it to our previous method, in which we quantified the area of the ROI with colorimetric signal above a threshold based on multiple background measurements (Heimovics et al. 2012, Tomm et al. 2018). For FOSB-ir quantification, 
number of FOSB-ir nuclei were counted in the region of interest using TMARKER (Wild et al. 2013), where the images underwent colour deconvolution and detection parameters were adjusted (tolerance $=5$; blur $=1$ ) .

\section{Data analyses}

For GTT, body mass, and adipose depot mass, a repeated measure mixed model ANOVA was used to examine the fixed factor effects and two-factor interactions, with individual as a random factor. Only the main effect of diet is reported due to the absence of significant twofactor interactions (the interactions terms remained in the model). For analysis of food consumption, the weekly average of daily food consumed was computed for all pairhoused individuals and used to represent a single value for those two females (e.g. $n=5$ values/group). For analysis of insulin, we were only able to collect enough plasma for measurements from five control-fed animals and eight sucrose-fed animals. Moreover, fasting glucose levels were only able to be measured in five control-fed animals and six sucrose-fed animals due to sample loss. Therefore, the quantitative insulin sensitivity check index (QUICKI) had sample sizes of five and six for control and sucrose-fed animals, respectively.

The mRNA levels in the gonadal adipose tissue were examined using a two-way ANOVA with diet and gene as the explanatory variables. Effects of diet were assessed using Sidak's multiple comparison test, and no further corrections for multiple statistical testing were performed. Adjusted $P$-values are reported.

For the qualitative analysis of hepatic histology, a $\chi^{2}$ test of goodness-of-fit was performed to assess differences in frequency of steatosis and a two-sided Fisher's exact test to assess cell ballooning. Portal inflammation was not present in any hepatic samples and therefore was not analysed.

For steroid analysis, a value was considered nondetectable if it was below the lowest point on the calibration curve (i.e. the limit of quantification; LOQ). If more than $20 \%$ of the values were above the LOQ in both groups, then the missing values were estimated via quantile regression imputation of left-censored missing data (Wei et al. 2018). If less than $20 \%$ of the values were above the LOQ in either group, then inferential statistics were not performed and only descriptive statistics were reported. In order to compare serum and brain steroid concentrations, we estimated that $1 \mathrm{~mL}$ of serum weighs $1 \mathrm{~g}$ (Schmidt \& Soma 2008, Taves et al. 2011). For each steroid, a linear mixed model was used to determine the effect of diet. Here, diet and brain region were the fixed factors, and animal ID was a random factor to control for pseudo-replication of steroid measurements within an animal. There were no statistical adjustments made for examining multiple steroids, because corticosterone and progesterone were the only steroids that were present in all tissues in both diets and thus the only steroids assessed using a full-mixed model that included all interaction terms.

For all other endpoints, a two-tailed independent $t$-test was used to determine differences between diets. For data that did not exhibit homoscedasticity, an unpaired $t$-test with Welch's correction was used (e.g. liver mass as a percent of body mass). For all analyses, $\alpha$ was set at $\leq 0.05$. All graphs are presented using non-transformed data. All statistics were conducted using IBM SPSS Statistics for Windows version 23 (IBM Corp), GraphPad Prism version 6.00 (GraphPad Software), and R version 3.6.0 (2019-0426; 'Planting a Tree') (https://www.r-project.org/) using the 'nlme' package (Pinheiro et al. 2019).

\section{Results}

\section{Chronic sucrose consumption did not affect body mass, offspring sex ratio, offspring mass, or litter size}

The amount of food (and calories) consumed did not significantly differ between diet groups over the first 10 weeks (diet $\times$ time: $F_{9,36}=0.858, P=0.569$; Fig. 2A). Moreover, body mass did not significantly differ between diet groups throughout the entire study $\left(\mathrm{F}_{1,14}=0.69\right.$, $P=0.421$; Fig. 2B). Diet did not significantly influence offspring sex ratio (Welch-corrected $\mathrm{t}_{10.1}=1.280, P=0.229$ ), offspring mass at birth $\left(\mathrm{t}_{14}=1.832, P=0.088\right)$, litter size $\left(\mathrm{t}_{14}=0.831, P=0.420\right)$, or postnatal mortality (Welchcorrected $t_{9.52}=1.377, P=0.200$; Supplementary Table 1 ).

\section{Chronic sucrose consumption impaired glucose tolerance}

The sucrose diet significantly impaired the ability to regulate glucose at the post-weaning timepoint (effect of diet: $\left.\mathrm{F}_{1,14}=4.63, P=0.049\right)$ but not at the pre-conception timepoint (effect of diet: $\mathrm{F}_{1,14}=2.062, P=0.173$; Fig. 3). At the pre-conception timepoint, fasting insulin levels did not significantly differ between the two groups $\left(\mathrm{t}_{11}=0.58\right.$, $P=0.574$ ), and the QUICKI was not significantly different between the two groups $\left(t_{9}=1.319, P=0.220\right.$; Supplementary Table 2). 

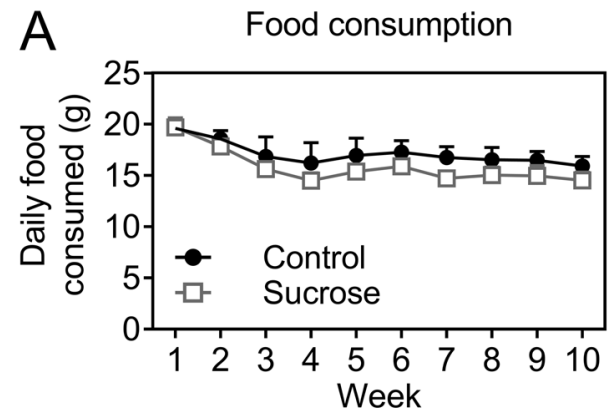

B

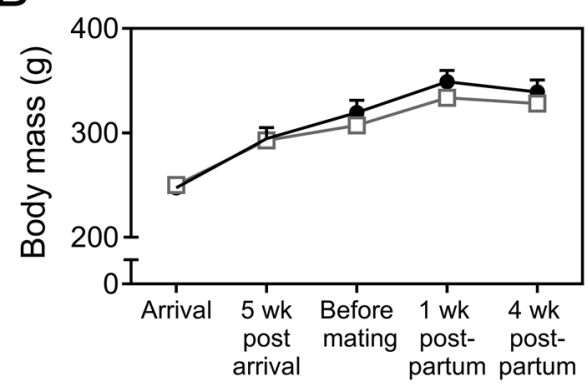

Figure 2

Food consumption and body mass. (A) The line graph represents food consumption as the daily amount ( $\mathrm{g}$ ) of food consumed from the start of their respective diet to mating (10 weeks). Females given the same diet were pair-housed during this period, so food consumption is an average of total amount of food consumed per week divided by two. (B) The line graph represents the body mass of each diet group throughout the study (arrival to killing) at each major point during the study. Data are presented as mean + S.E.M.

\section{Chronic sucrose consumption increased liver lipids}

The sucrose diet significantly increased relative liver mass (percentage of body mass; Welch-corrected $\mathrm{t}_{8.89}=2.512$, $P=0.034$; Fig. 4A). In addition, sucrose-fed dams had significantly higher hepatic lipids (Welch-corrected $\mathrm{t}_{11.49}=2.552, P=0.026$; Fig. $\left.4 \mathrm{~B}\right)$, hepatic steatosis $\left(\chi^{2}(\mathrm{df}=2\right.$, $n=16)=9.808, P=0.007$; Fig. $4 \mathrm{C}$ and D), and higher hepatic cell ballooning that approached significance (two-sided Fisher's exact test $(n=16), P=0.089$; Supplementary Table 3$)$.

\section{Chronic sucrose consumption affected visceral adipose depots}

The relative mass of total visceral adipose (percentage of body mass) did not significantly differ between control and sucrose females $\left(\mathrm{t}_{14}=1.685, P=0.114\right)$. However, when analysed with a mixed model ANOVA, there was a significant diet $\times$ depot interaction $\left(\mathrm{F}_{2,28}=9.062\right.$, $P=0.0009)$. Sidak's multiple comparison tests revealed that the perirenal/retroperitoneal adipose depot weighed significantly less in sucrose females $\left(P_{a d j}=0.007\right)$ (Fig. 5A).
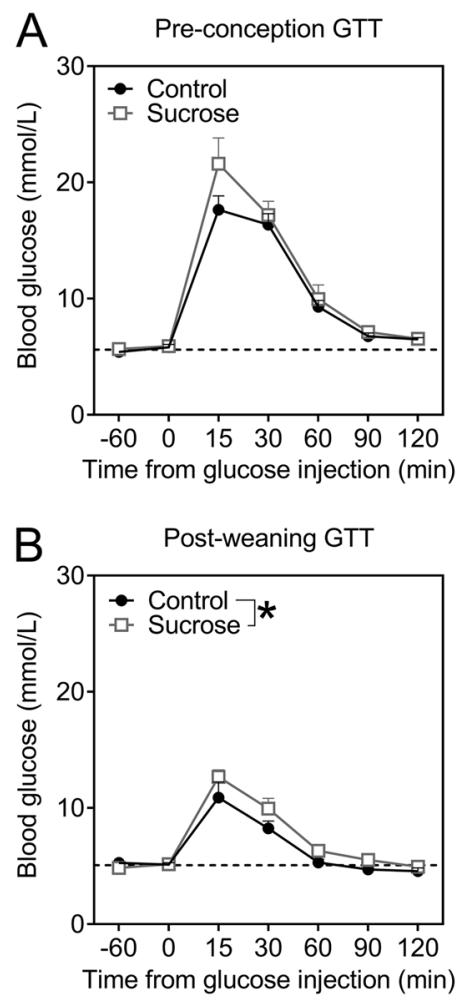

Figure 3

Sucrose consumption impairs glucose tolerance. (A and B) Line graphs representing blood glucose levels ( $\mathrm{mmol} / \mathrm{L}$ ) during a glucose tolerance test (GTT) in control-fed and sucrose-fed females at (A) pre-conception and (B) post-weaning. Data are presented as mean + S.E.M. $* P<0.05$.

In gonadal adipose tissue surrounding the uterine horns, we examined mRNA levels of the macrophagespecific Emr1 and the proinflammatory cytokines Tnf (TNF $\alpha$ ) and Il1b (IL-1 $\beta$ ) via multiple $t$-tests with Holm-Sidak corrected $P$-values. Sucrose-fed dams had significantly higher levels of Emr1 mRNA (t-ratio $=2.635$, $\mathrm{df}=42, P_{\text {adj }}=0.012$ ) but not Tnf mRNA (t-ratio $<0.01$, $\left.\mathrm{df}=42, P_{\text {adj }}=0.999\right)$ or $I l 1 b$ mRNA (t-ratio $=0.23, \mathrm{df}=42$, $\left.P_{\text {adj }}>0.999\right)$ (Fig. 5B).

\section{Chronic sucrose consumption altered corticosterone and progesterone levels}

Using ultra-sensitive and specific LC-MS/MS, we measured a panel of eight steroids in the serum and multiple microdissected brain regions. Sucrose intake had the greatest effects on corticosterone and progesterone (Fig. 6 and Tables 2,3). There was a significant diet $\times$ tissue interaction for corticosterone $\left(\mathrm{F}_{6,80}=2.89 ; P=0.013\right)$, and post-hoc analyses revealed that the sucrose diet significantly decreased corticosterone levels in the serum but not in the brain (Fig. 6A). The sucrose diet did not 


\section{B Hepatic lipids}
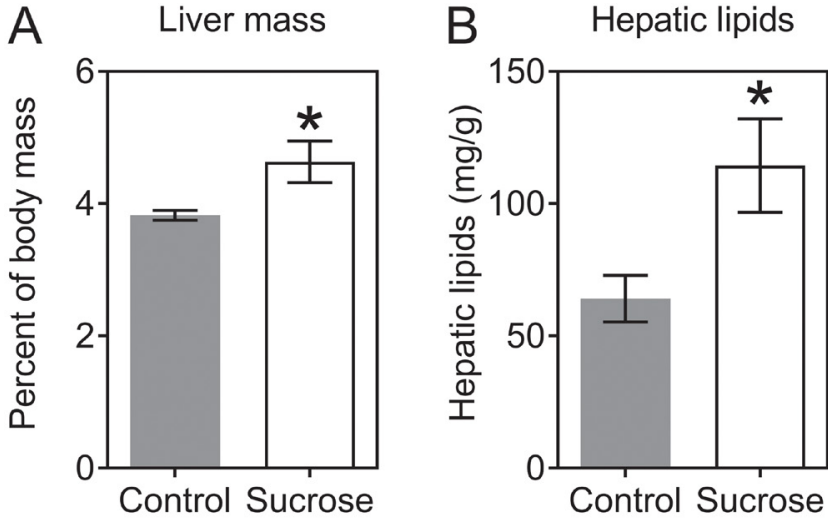

C Hepatic steatosis

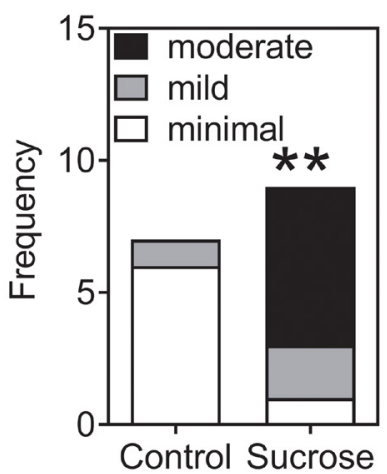

$\mathrm{D}$

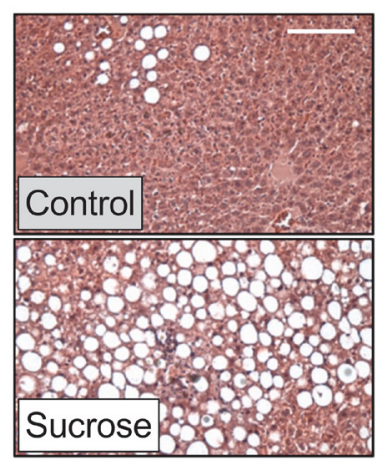

Figure 4

Sucrose consumption increases liver mass and liver lipids. (A) Bar graphs representing liver mass as percent of body mass. Dams fed with the sucrose diet had significantly higher relative liver mass than control dams. (B) Bar graph representing hepatic lipids (mg) per each g of tissue as measured by gravimetric quantification. (C) Stacked bar graph representing the frequency of minimal (score $=0(<5 \%)$ ), mild (score $=1$ $(5-33 \%))$, or moderate (score $=2(34-66 \%))$ steatosis as determined by a pathologist blind to treatment using the NASH CRN scoring system. (D) Representative photomicrographs of H\&E-stained liver sections. White, circular objects are abnormal hepatic lipid deposits, indicative of steatosis. Scale bar, $100 \mu \mathrm{m}$. (A and B) Data are presented as mean \pm S.E.M. $* \star P<0.01 ; * P<0.05$.

significantly affect the brain:serum ratio of corticosterone $\left(\mathrm{F}_{1,59}=1.16 ; P=0.28\right.$; Fig. $\left.6 \mathrm{C}\right)$. In contrast, sucrose intake significantly increased progesterone levels in both serum and brain (main effect of diet: $\mathrm{F}_{1,65}=5.89 ; P=0.046$; Fig. $6 \mathrm{~B}$ ) and increased the brain:serum ratio of progesterone (main effect of diet: $\mathrm{F}_{1,39}=10.75 ; P=0.002$; Fig. $6 \mathrm{D}$ ).

For androstenedione, pregnenolone, and testosterone (Tables 2 and 3), several interesting patterns emerged. First, androstenedione was detectable in the serum and all brain regions, except the VTA. Second, pregnenolone was detectable in all mPFC samples, but it was rarely detectable in serum or other brain regions. Third, testosterone was detectable in all serum samples, but it was rarely detectable in HPC and POA/HYP and was

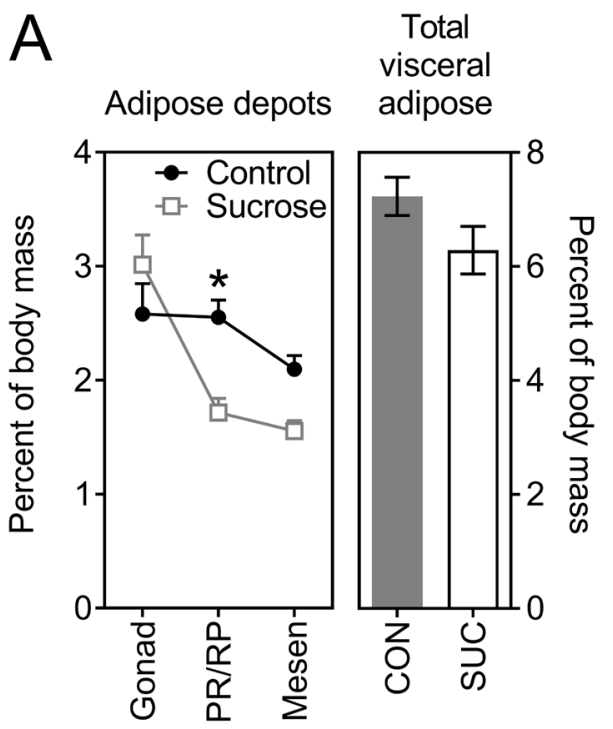

B Inflammatory

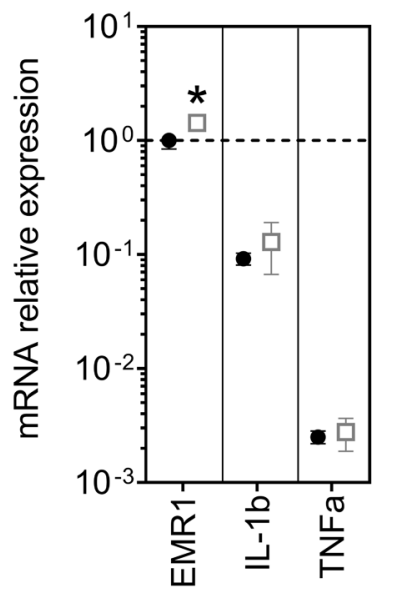

Figure 5

Sucrose consumption affects adipose depots. (A) Line graph represents relative mass of the gonadal adipose depot ('Gonad'), perirenal/ retroperitoneal adipose depot ('PR/RP'), and mesenteric adipose depot ('Mesen'), while the adjacent bar graph represents the relative mass of total visceral adipose (the three depots combined). (B) Graphs represent the relative expression of EMR1, IL-1 $\beta$, and TNF $\alpha$ transcripts in gonadal adipose tissue, as calculated by the $2^{-(\Delta \Delta C t)}$ method using $18 \mathrm{~S}$ rRNA as the reference gene. Note the log-scale on the $y$-axis. Data are presented as mean \pm S.E.M. $* P<0.05$.

non-detectable in mPFC, NAc, and VTA. Finally, testosterone was detectable in sucrose-fed dams in the dHPC (33\%) and vHPC (44\%), but it was rarely detectable in control dams in both HPC subregions (14\%). DHEA, DHT, and $\mathrm{E}_{2}$ were not detectable in the serum or brain samples. Overall, there is some evidence of the possibility of an effect of chronic sucrose consumption on androstenedione, pregnenolone, and testosterone. However, we interpret these results cautiously due to 
A

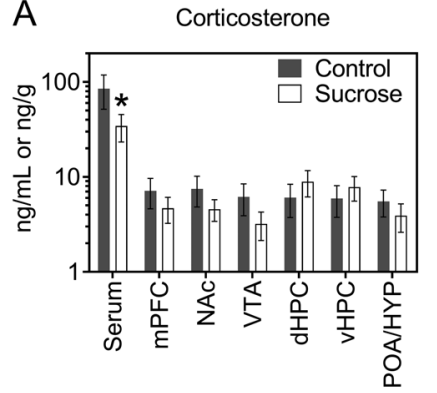

B

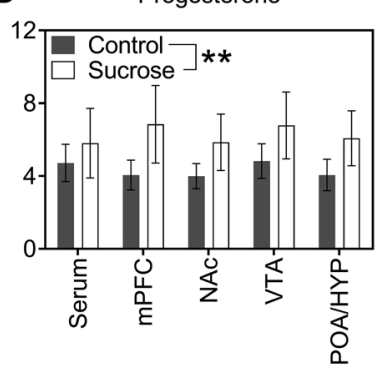

C

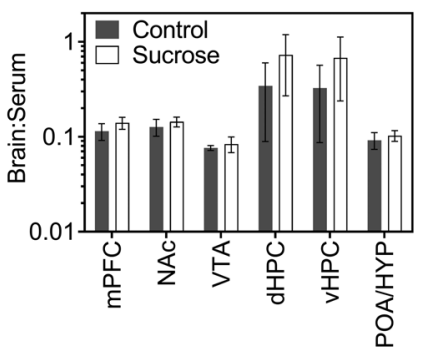

$\mathrm{D}$

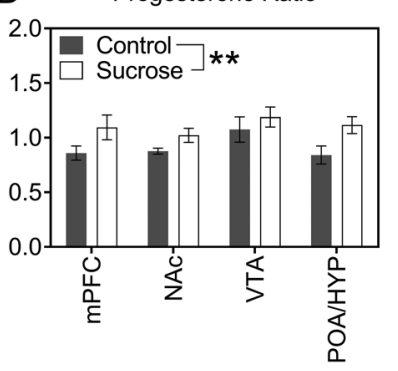

Figure 6

Sucrose consumption decreases serum corticosterone and increases serum and neural progesterone. (A and B). Graphs represent steroid concentrations of $(A)$ corticosterone and $(B)$ progesterone in the serum, mesocorticolimbic system, hippocampus (HPC), and preoptic area/ hypothalamus (POA/HYP). (C and D) Graphs represent the ratio of brain-to-serum (brain:serum) (C) corticosterone and (D) progesterone. Note the log-scale on the $y$-axis in ( $A$ and $C)$. Data are presented as mean \pm S.E.M. ${ }^{*} P<0.05,{ }^{*} * P<0.01$. mPFC, medial prefrontal cortex; NAC, nucleus accumbens; dHPC, dorsal hippocampus; vHPC, ventral hippocampus; VTA, ventral tegmental area. Progesterone was not quantified in the HPC because of high matrix interference.

insufficient sample sizes to detect moderate differences in binary measures (i.e. presence/absence).

\section{Chronic sucrose consumption decreased TH-ir and altered the pattern of FOSB-ir in the mesocorticolimbic system}

The sucrose diet significantly reduced $\mathrm{TH}$-ir in both subregions of the mPFC (effect of diet: $F_{1,28}=7.79$; $P=0.009$; Fig. 7). Furthermore, there was a trend for a reduction of TH-ir in both subregions of the NAc (effect of diet: $\left.\mathrm{F}_{1,28}=3.829 ; P=0.060\right)$. There were no significant effects of diet on TH-ir in the VTA $\left(\mathrm{t}_{15}=0.007 ; P=0.994\right)$ or OFC $\left(\mathrm{F}_{1,28}=1.751 ; P=0.196\right)$. TH-ir was significantly higher in the medial OFC than the lateral OFC (effect of subregion: $\mathrm{F}_{1,28}=20.90 ; P<0.0001$ ), regardless of diet.

For FOSB-ir, sucrose intake did not have a significant main effect in any of the brain regions (Fig. 8). Specifically, there was no effect of diet in the OFC (medial OFC (control: 92.93 \pm 19.19 ; Sucrose: 89.63 \pm 12.97 ); lateral

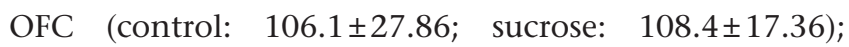

Table 2 Serum and mesocorticolimbic steroid concentrations (ng/ $\mu \mathrm{L}$ or ng/g) as analyzed by LC-MS/MS in control-fed $(n=7)$ and sucrose-fed $(n=9)$ rat dams.

\begin{tabular}{|c|c|c|}
\hline & Control & Sucrose \\
\hline \multicolumn{3}{|l|}{ Seruma } \\
\hline Androstenedione & $0.08 \pm 0.04$ & $0.11 \pm 0.04$ \\
\hline Corticosterone & $85.0 \pm 33.4$ & $34.4 \pm 11.1$ \\
\hline Pregnenolone & n.d. & $(11.9)$ \\
\hline Progesterone & $4.72 \pm 1.03$ & $5.81 \pm 1.91$ \\
\hline Testosterone & $0.06 \pm 0.01$ & $0.07 \pm 0.02$ \\
\hline \multicolumn{3}{|c|}{ Medial prefrontal cortex } \\
\hline Androstenedione & $0.58 \pm 0.35$ & n.d. \\
\hline Corticosterone & $7.15 \pm 2.52$ & $4.68 \pm 1.43$ \\
\hline Pregnenolone & $47.6 \pm 5.33$ & $51.4 \pm 5.41$ \\
\hline Progesterone & $4.05 \pm 0.82$ & $6.85 \pm 2.13$ \\
\hline Testosterone & n.d. & n.d. \\
\hline \multicolumn{3}{|l|}{ Nucleus accumbens } \\
\hline Androstenedione & $0.27 \pm 0.15$ & $0.08 \pm 0.04$ \\
\hline Corticosterone & $7.50 \pm 2.68$ & $4.58 \pm 1.17$ \\
\hline Pregnenolone & n.d. & $(83.00)$ \\
\hline Progesterone & $4.00 \pm 0.69$ & $5.86 \pm 1.55$ \\
\hline Testosterone & n.d. & n.d. \\
\hline \multicolumn{3}{|c|}{ Ventral tegmental area } \\
\hline Androstenedione & n.d. & n.d. \\
\hline Corticosterone & $5.18 \pm 2.28$ & $3.20 \pm 1.06$ \\
\hline Pregnenolone & $(47.9)$ & $67.8 \pm 20.9$ \\
\hline Progesterone & $4.82 \pm 0.95$ & $6.78 \pm 1.83$ \\
\hline Testosterone & n.d. & n.d. \\
\hline
\end{tabular}

Data are presented as mean \pm S.E.M.

aNote that four serum samples were lost during processing ( $n=6 /$ group). Values in parentheses are shown when the group only had one detectable sample.

n.d., not detectable; $17 \beta$-estradiol, DHEA, and $5 \alpha$-dihydrotestosterone were not detected in any of the samples.

effect of diet $\left.\left(\mathrm{F}_{1,13}<0.001, P=0.98\right)\right)$, $\mathrm{mPFC}\left(\mathrm{F}_{1,14}=0.0163\right.$, $P=0.90)$, or NAc $\left(\mathrm{F}_{1,14}=0.2273, P=0.64\right)$. Note that one animal from the control group in the OFC $(n=6)$ was missing completely at random due to experimenter error. Interestingly, there was a significant diet $\times$ subregion (core vs shell) interaction in the NAc $\left(\mathrm{F}_{1,14}=7.607, P=0.015\right)$. Control-fed dams had higher FOSB-ir in the core than the shell, while sucrose-fed dams exhibited the opposite pattern and had higher FOSB-ir in the shell than the core.

\section{Discussion}

Overall, chronic sucrose consumption had widespread and marked significant effects on metabolism, steroid levels in blood and brain, and markers of DA synthesis and signalling in the mesocorticolimbic system of parous female rats. We used a human-relevant level of sucrose intake $(25 \% \mathrm{kcal})$ and compared it to an isocaloric and macronutrient-matched control diet over a long period (17-18 weeks). In contrast, many previous studies have 
Table 3 Hippocampal and preoptic area/hypothalamus steroid concentrations ( $\mathrm{ng} / \mathrm{\mu L}$ or $\mathrm{ng} / \mathrm{g}$ ) as analyzed by LC-MS/MS in control-fed $(n=7)$ and sucrose-fed $(n=9)$ rat dams.

\begin{tabular}{l}
\hline \\
\hline Hippocampus - dorsal \\
Androstenedione \\
Corticosterone \\
Pregnenolone \\
Progesterone \\
Testosterone \\
Hippocampus - ventral \\
Androstenedione \\
Corticosterone \\
Pregnenolone \\
Progesterone \\
Testosterone \\
Preoptic area/ \\
hypothalamus \\
Androstenedione \\
Corticosterone \\
Pregnenolone \\
Progesterone \\
Testosterone
\end{tabular}

\begin{tabular}{c}
\hline Control \\
\hline $0.11 \pm 0.03$ \\
$6.06 \pm 2.32$ \\
$(19.1)$ \\
$6.17 \pm 1.26$ \\
$(0.07)$ \\
$0.07 \pm 0.03$ \\
$5.93 \pm 2.17$ \\
$(14.8)$ \\
$6.99 \pm 1.31$ \\
$(0.08)$ \\
\\
$0.22 \pm 0.13$ \\
$5.54 \pm 1.75$ \\
$n . d$. \\
$4.06 \pm 0.87$ \\
$0.22 \pm 0.10$ \\
\hline
\end{tabular}

Data are presented as mean \pm S.E.M. Values in parentheses are shown when the group only had one detectable sample.

n.d., not detectable; $17 \beta$-estradiol, DHEA, and $5 \alpha$-dihydrotestosterone were not detected in any of the samples.

used very high levels of sucrose or fructose ( $>50 \% \mathrm{kcal})$ for short periods (1-2 weeks) (Bursać et al. 2014, Kjaergaard et al. 2014, Vasiljević et al. 2014, Lesser et al. 2017). We gave the sucrose in the diet instead of in the water,

because animals with sucrose or fructose in the water eat less and thus consume less protein, fat, vitamins, and minerals (Ohashi et al. 2015). The present approach avoids group differences in the consumption of protein, fat, vitamins, and minerals. Here, there were also no significant group differences in food (energy) intake, body mass, or total visceral adipose, and thus the effects of sucrose seen here are independent of caloric consumption and obesity. In this study, we examined the effects of sucrose on parous females only, and future work will examine nulliparous females as well as males.

Little is known about how chronic sucrose intake influences steroids and neurotransmitters. Here, sucrose significantly decreases corticosterone levels in serum, but increases progesterone levels in serum and brain and increases the brain:serum progesterone ratio in all regions. To our knowledge, this is the first time that steroid profiling has been performed in microdissected regions of the female rodent brain. Sucrose consumption significantly decreases TH-ir in the mPFC, with a similar trend in the NAc, suggesting a decrease in DA synthesis in the mesocorticolimbic system, which is critical for reward seeking and decision making. Lastly, sucrose consumption significantly alters the pattern of FOSB-ir within the NAc. Overall, these results show that chronic intake of a human-relevant level of dietary sucrose has wide-ranging effects on physiology, including the endocrine and nervous systems.

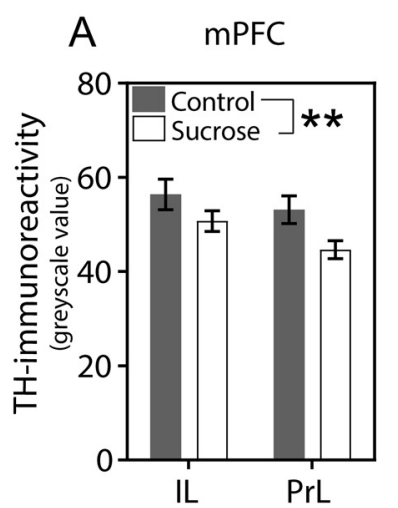

C

VTA
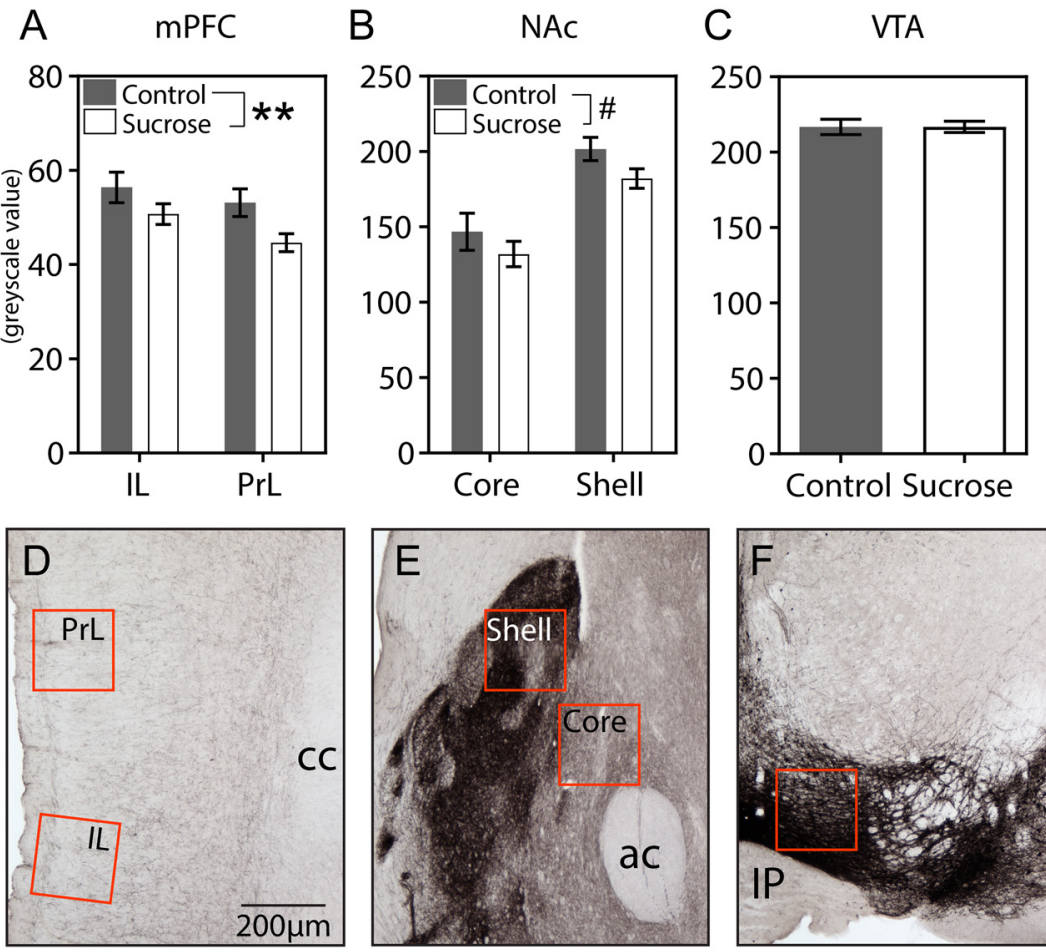

Figure 7

Sucrose consumption decreases tyrosine hydroxylase-immunoreactivity ( $\mathrm{TH}$-ir) in the mesocorticolimbic system. (A, B, and C) Bar graphs represent overall photomicrograph pixel intensity that corresponds to $\mathrm{TH}$-ir in the (A and D) infralimbic (IL) and prelimbic (PrL) medial prefrontal cortex (mPFC), (B and E) the core and shell of the nucleus accumbens (NAC), and ( $C$ and F) the ventral tegmental area (VTA) in control- and sucrose-fed subjects. (D, E, and F) Representative photomicrographs of the mesocorticolimbic nodes with regions of interest outlined in red, used in the quantification of (D) MPFC, (E) NAc, and (F) the VTA. Data are presented as mean \pm S.E.M. ${ }^{*}$ Significant effect of diet $(P<0.01)$. \#Effect of diet $(P=0.06)$. cc, corpus callosum; ac, anterior commissure; IP, interpeduncular nucleus. https://joe.bioscientifica.com https://doi.org/10.1530/JOE-19-0386
(C) 2020 Society for Endocrinology Published by Bioscientifica Ltd. Printed in Great Britain 
A
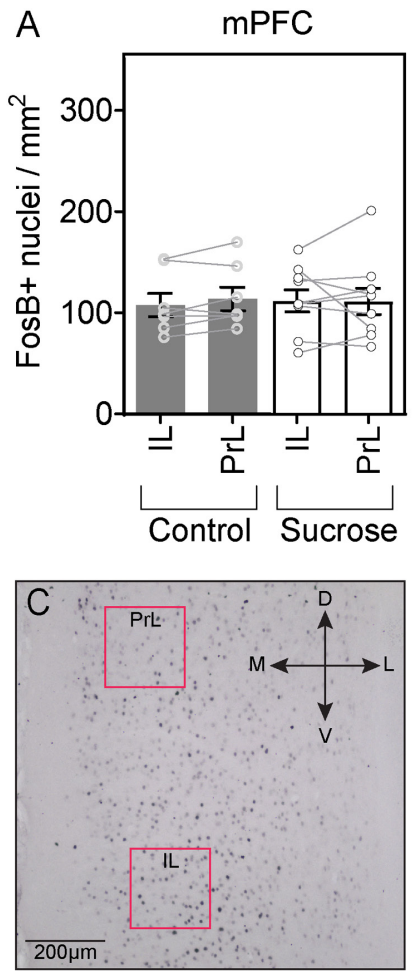
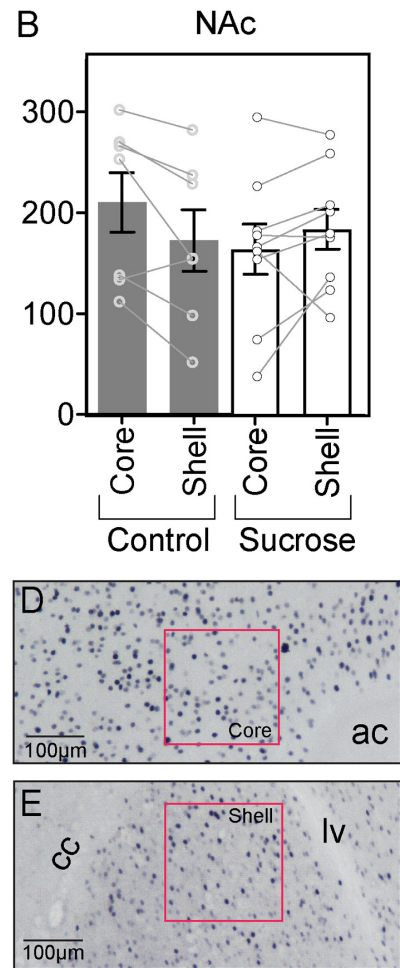

\section{Figure 8}

Sucrose consumption alters the pattern of FOSB-immunoreactivity in the nucleus accumbens. Bar graphs represent FOSB-ir nuclei in the (A) infralimbic (IL) and prelimbic (PrL) medial prefrontal cortex (mPFC), (B) core and shell of the nucleus accumbens (NAC) in control- and sucrose-fed subjects. (C and D) Representative photomicrographs of the mesocorticolimbic nodes with regions of interest outlined in red, used in the quantification of (C) MPFC and (D) NAc. Note that FOSB-ir in the VTA was sparse and thus not quantified. Data are presented as mean \pm S.E.M.

\section{Effects of sucrose consumption on metabolism}

The sucrose diet significantly reduced the ability to regulate blood glucose at the post-weaning timepoint (after 17-18 weeks) but not at the pre-conception timepoint (after 10 weeks). These data are consistent with previous studies showing that high sucrose or fructose consumption impairs glucose tolerance (Asghar et al. 2016, Saben et al. 2016). In the present study, the difference between the two timepoints might be attributable to the different durations of sucrose exposure or perhaps to endocrine differences in the dams. Interestingly, the sucrose-fed dams did not significantly gain more weight than control dams and did not show significant evidence of fasting hyperinsulinemia or hyperglycaemia, similar to previous studies (Lomba et al. 2009, Oliveira et al. 2014).

Hepatic lipids were significantly increased in sucrosefed dams. This is consistent with previous studies (Oliveira et al. 2014). Sucrose consumption significantly increased hepatic lipids, steatosis, relative liver mass, triglycerides,

and showed a trend to increase hepatocellular ballooning. These data provide further evidence that a humanrelevant level of sucrose consumption can contribute to the development of non-alcoholic steatohepatitis (see Michelotti et al. 2013 for review).

We also examined visceral fat mass relative to body size. Total visceral fat mass relative to body size did not significantly differ between the control- and sucrosefed groups. These findings differ from some previous studies in rodents (Lomba et al. 2009). In rodents, sucrose consumption does not increase visceral adiposity in all studies. For example, Oliveira et al. (2014) reported that in male mice fed a high-sucrose diet, there is no effect on visceral adiposity. Many variables (e.g. sex, parity, species, dietary fat, sucrose content, duration, etc.) might affect how sucrose impacts visceral adiposity. Pregnancy and lactation affect visceral adipose distribution (Steingrimsdottir et al. 1980), and in this study, diet and pregnancy might have interacted to change the distribution of visceral adipose. Nonetheless, total visceral adiposity did not significantly differ between the groups. This is important because an increase in adiposity can have effects on metabolism, steroids, and the brain (Bray 1997, Bruce-Keller et al. 2009). With this model, we can examine how sucrose intake, independent of caloric intake and total visceral adiposity, affects metabolism, steroids, and DA signalling.

Sucrose-fed dams showed some evidence of inflammation in the gonadal adipose tissue. Sucrosefed dams had a significant increase in the macrophagespecific transcript Emr1 in gonadal adipose. However, transcripts for two proinflammatory cytokines released by macrophages, TNF- $\alpha$ and IL- $1 \beta$, did not significantly differ between groups. These data suggest that sucrose consumption increases macrophage number or activity in the adipose tissue surrounding the uterine horns. Overall, these results provide partial evidence that sucrose induces latent inflammation in adipose tissue (Stafeev et al. 2017).

\section{Effects of sucrose consumption on systemic and neural steroid levels}

Pregnancy and lactation are marked by profound changes in steroids, including glucocorticoids, progestins, and oestrogens (Kovacs 2016). Here, sucrose consumption during pregnancy and lactation significantly alters both corticosterone and progesterone levels. Notably, we used state-of-the-art LC-MS/MS to measure a panel of steroids with great specificity and sensitivity in blood and microdissected brain regions. 
Chronic sucrose consumption significantly reduces baseline levels of serum corticosterone. This effect might be a regulatory mechanism to prevent even higher levels of circulating glucose resulting from corticosteroneinduced glycogenolysis or gluconeogenesis. In contrast, some rodent studies have reported that sucrose or fructose increases circulating corticosterone (Hart et al. 1980, Gaysinskaya et al. 2011, Choi et al. 2017). However, these studies examined the effects of acute or short-term sucrose consumption and all focused on male rodents. A longer-term study by Corona-Pérez et al. (2017) used 8 weeks of sucrose exposure in male rats and found that sucrose lowered corticosterone levels. The longterm exposure and/or female subjects used here might explain the differences across studies. Moreover, sucrose consumption tended to decrease corticosterone levels in the brain, except the HPC. Interestingly, consumption of highly palatable foods, which includes sucrose, reduces the corticosterone response in stressed animals, thereby reducing stress-induced behaviours (Pecoraro et al. 2004).

The sucrose-induced decrease in circulating corticosterone may also partly explain the metabolic and immune effects observed. First, corticosterone increases circulating glucose levels (McMahon et al. 1988), yet we report significantly lower serum corticosterone and higher blood glucose in sucrose dams during the postweaning GTT. Contrary to our findings, an acute increase in corticosterone improves glucose regulation during a GTT (Tirosh et al. 2010). However, many previous studies used acute corticosterone manipulations and do not give much insight into how basal corticosterone levels after chronic sucrose consumption may influence glucose regulation (Rafacho et al. 2014). Second, the sucroseinduced decrease in corticosterone might explain the increase in the macrophage-specific marker (Emr1) in the gonadal adipose tissue. Chronic increases in corticosterone are immunosuppressive, whereas lower levels of corticosterone can promote immune system reactivity (Taves et al. 2017). Thus, lower levels of corticosterone in the sucrose-fed dams may lead to increased macrophages in adipose.

In contrast to corticosterone, progesterone is significantly increased in the serum and brain of sucrosefed dams. Progesterone can increase hepatic lipogenesis and triglycerides (Dahm et al. 1977). Thus, the increase in hepatic steatosis in sucrose-fed dams may be due, in part, to an increase in progesterone along with a decrease in corticosterone. The brain-to-serum progesterone ratio is also elevated in sucrose-fed dams. This suggests that sucrose intake increases neural progesterone synthesis or accumulation. Increased progesterone synthesis is likely for several reasons. First, regions with elevated progesterone ratio express the enzymes for progesterone synthesis (Kimoto et al. 2010, Tobiansky et al. 2018b). Second, brain slice cultures actively synthesize progesterone de novo (Hojo et al. 2009). Third, pregnenolone, the precursor to progesterone, was detectable in the mPFC of nearly all rat dams. Of the brain regions examined, the mPFC had one of the highest group differences in progesterone ratio. The high levels of pregnenolone suggest that the increase in progesterone ratio is due to synthesis. Taken together, these results suggest that sucrose consumption alters progesterone levels in regions that regulate reward seeking and motivation (Ducharme et al. 2010).

Finally, androstenedione and testosterone were not significantly affected by sucrose intake. However, future studies should have larger sample sizes to assess effects of sucrose intake on androstenedione and testosterone, due to low circulating levels of these steroids in females. DHEA, DHT, and $\mathrm{E}_{2}$ were non-detectable in all samples. Circulating $\mathrm{E}_{2}$ in female rats are quite low during lactation (Kovacs 2016). We are currently developing more sensitive LC-MS/MS methods for DHEA and $\mathrm{E}_{2}$ measurement.

\section{Sucrose alters DA signalling in the mesocorticolimbic system}

Surprisingly, there is little known about how chronic sucrose intake affects DA signalling. Here, chronic sucrose consumption significantly decreased $\mathrm{TH}$, the rate-limiting enzyme for DA synthesis, in the mPFC and there was a trend towards a decrease in the NAc. Similarly, long-term access to sucrose in the drinking water (10\%) decreases TH-ir in the striatum (Ahmed et al. 2014). One way in which chronic sucrose consumption can decrease $\mathrm{TH}$ in the striatum and mPFC is via an increase in progesterone (as seen here); progesterone decreases TH mRNA in the brain (Arbogast \& Voogt 1994). Lower TH in the NAc and mPFC of sucrosefed dams can lead to important behavioural differences. DA signalling in the mPFC is particularly sensitive to sucrose and fat consumption. Prefrontal DA signalling is dysregulated by intermittent access to sucrose, causing deficits in instrumental learning, which are rescued by administration of a DA D2 receptor $\left(\mathrm{D}_{2} \mathrm{R}\right)$ antagonist (Sharpe et al. 2016). Decreases in DA synthesis in the rat $\mathrm{mPFC}$ and NAc impact goal-directed behaviours (Cacciapaglia et al. 2011) and maternal behaviours (Keer \& Stern 1999). To our knowledge, no studies have examined the possible effects of sucrose consumption on maternal behaviour, and this is an important question for future studies to address. 
Sucrose consumption might also impact DA signalling in the NAc, as suggested by the FOSB-ir results. Controls had significantly higher FOSB-ir in the NAc core than shell, whereas sucrose-fed dams had significantly higher FOSB-ir in the NAc shell than core. This is important because sustained changes in phasic DA signalling in the NAc due to repeated exposure to rewarding stimuli (e.g. sugar) upregulates the stable form of the transcription factor FOSB, $\triangle \mathrm{FOSB}$, which is implicated in addictive-like behaviours (e.g. binge eating (Robison \& Nestler 2011)). Therefore, these data suggest that there is higher phasic DA release in the NAc shell (vs core) in sucrose-fed individuals. Indeed, daily binging on sucrose increases DA release in the NAc shell (Rada et al. 2005). Daily access to sucrose also increases $\mathrm{D}_{1} \mathrm{R}$ and decreases $\mathrm{D}_{2} \mathrm{R}$ in the NAc (Avena et al. 2008). These changes in DA signalling are associated with alterations in DA-dependent behaviours (Arbogast \& Voogt 2002, Kendig et al. 2014).

\section{Conclusions}

The results from this study are particularly compelling because we used a human-relevant level of sucrose intake over a long period of time and we examined multiple physiological systems. Moreover, these results provide insight into the effects of sucrose on female physiology, which is lacking in the literature. Overall, the data are consistent with previous metabolic studies showing that sucrose consumption significantly impairs glucose tolerance, increases liver lipids, and increases adipose inflammation. Further, our steroid analyses via LC-MS/MS reveal that chronic sucrose intake significantly decreases circulating corticosterone levels. On the other hand, progesterone and the progesterone ratio are significantly increased by the sucrose diet, suggesting a change in brain steroidogenesis. Finally, sucrose intake significantly reduces $\mathrm{TH}$-ir and alters FOSB-ir in important mesocorticolimbic nodes associated with reward seeking and motivated behaviour. Overall, these results show that a human-relevant level of dietary sucrose has wide-ranging effects on the whole body, including the endocrine and nervous systems.

\section{Supplementary materials}

This is linked to the online version of the paper at https://doi.org/10.1530/ JOE-19-0386.

\section{Declaration of interest}

The authors declare that there is no conflict of interest that could be perceived as prejudicing the impartiality of the research reported.

\section{Funding}

This research was supported by Canadian Institutes of Health Research Project Grant to K K S (168928), a Canada Foundation for Innovation Grant to K K S, and a Bluma Tischler Postdoctoral Fellowship to D J T.

\section{Acknowledgements}

The authors thank Chunqi Ma, Cecilia Jalabert, Melody Salehzadeh, Helen Schweitzer, Marie Turcott, Whitney Krieger, Ravish Sharma, Jasmine Cleary-Gosine, Cheryl Chow, Dinushi Wickrama, Brandon Forys, Maric Tse, Courtney Bryce, Mieke van Holstein, Grace Truong, and Robert Whitwell for their assistance with experimental design, data collection, and data analysis; Catharine Winstanley for providing access to equipment; and Eric Schuppe for comments on the manuscript.

\section{References}

Ahmed S, Kashem MA, Sarker R, Ahmed EU, Hargreaves GA \& McGregor IS 2014 Neuroadaptations in the striatal proteome of the rat following prolonged excessive sucrose intake. Neurochemical Research 39 815-824. (https://doi.org/10.1007/s11064-014-1274-6)

Arbogast LA \& Voogt JL 1994 Progesterone suppresses tyrosine hydroxylase messenger ribonucleic acid levels in the arcuate nucleus on proestrus. Endocrinology 135 343-350. (https://doi.org/10.1210/ endo.135.1.7912184)

Arbogast LA \& Voogt JL 2002 Progesterone induces dephosphorylation and inactivation of tyrosine hydroxylase in rat hypothalamic dopaminergic neurons. Neuroendocrinology 75 273-281. (https://doi. org/10.1159/000057336)

Asghar ZA, Thompson A, Chi M, Cusumano A, Scheaffer S, Al-Hammadi N, Saben JL \& Moley KH 2016 Maternal fructose drives placental uric acid production leading to adverse fetal outcomes. Scientific Reports 6 25091. (https://doi.org/10.1038/srep25091)

Avena NM, Rada P \& Hoebel BG 2008 Evidence for sugar addiction: behavioral and neurochemical effects of intermittent, excessive sugar intake. Neuroscience and Biobehavioral Reviews 32 20-39. (https://doi. org/10.1016/j.neubiorev.2007.04.019)

Beilharz JE, Maniam J \& Morris MJ 2016 Short-term exposure to a diet high in fat and sugar, or liquid sugar, selectively impairs hippocampal-dependent memory, with differential impacts on inflammation. Behavioural Brain Research 306 1-7. (https://doi. org/10.1016/j.bbr.2016.03.018)

Bray GA 1997 Obesity and reproduction. Human Reproduction 12 (Supplement 1) 26-32. (https://doi.org/10.1093/humrep/12. suppl_1.26)

Bray GA 2010 Fructose: pure, white, and deadly? Fructose, by any other name, is a health hazard. Journal of Diabetes Science and Technology $\mathbf{4}$ 1003-1007. (https://doi.org/10.1177/193229681000400432)

Brown CM, Dulloo AG \& Montani JP 2008 Sugary drinks in the pathogenesis of obesity and cardiovascular diseases. International Journal of Obesity 32 (Supplement 6) S28-S34. (https://doi. org/10.1038/ijo.2008.204)

Bruce-Keller AJ, Keller JN \& Morrison CD 2009 Obesity and vulnerability of the CNS. Biochimica et Biophysica Acta 1792 395-400. (https://doi. org/10.1016/j.bbadis.2008.10.004 https://joe.bioscientifica.com https://doi.org/10.1530/JOE-19-0386 (c) 2020 Society for Endocrinology Published by Bioscientifica Ltd. Printed in Great Britain 
Bursać BN, Djordjevic AD, Vasiljević AD, Milutinović DDV, Veličković NA, Nestorović NM \& Matić GM 2013 Fructose consumption enhances glucocorticoid action in rat visceral adipose tissue. Journal of Nutritional Biochemistry 24 1166-1172. (https://doi.org/10.1016/j. jnutbio.2012.09.002)

Bursać BN, Vasiljević AD, Nestorović NM, Veličković NA, Vojnović Milutinović DD, Matić GM \& Djordjevic AD 2014 Highfructose diet leads to visceral adiposity and hypothalamic leptin resistance in male rats - do glucocorticoids play a role? Journal of Nutritional Biochemistry 25 446-455. (https://doi.org/10.1016/j. jnutbio.2013.12.005)

Buyukata C, Vukalo M, Xu TJ, Khore MA \& Reichelt AC 2018 Impact of high sucrose diets on the discrimination of spatial and object memories with overlapping features. Physiology and Behavior 192 127-133. (https://doi.org/10.1016/j.physbeh.2018.02.027)

Cacciapaglia F, Wightman RM \& Carelli RM 2011 Rapid dopamine signaling differentially modulates distinct microcircuits within the nucleus accumbens during sucrose-directed behavior. Journal of Neuroscience 31 13860-13869. (https://doi.org/10.1523/ JNEUROSCI.1340-11.2011)

Chen L, Xie YM, Pei JH, Kuang J, Chen HM, Chen Z, Li ZW, Fu XY, Wang L, Lai SQ, et al. 2018 Sugar-sweetened beverage intake and serum testosterone levels in adult males 20-39 years old in the United States. Reproductive Biology and Endocrinology 16 61. (https://doi. org/10.1186/s12958-018-0378-2)

Choi JY, Park MN, Kim CS, Lee YK, Choi EY, Chun WY \& Shin DM 2017 Long-term consumption of sugar-sweetened beverage during the growth period promotes social aggression in adult mice with proinflammatory responses in the brain. Scientific Reports $\mathbf{7} 45693$. (https://doi.org/10.1038/srep45693)

Corona-Pérez A, Díaz-Muñoz M, Cuevas-Romero E, Luna-Moreno D, Valente-Godínez H, Vázquez-Martínez O, Martínez-Gómez M, Rodríguez-Antolín J \& Nicolás-Toledo L 2017 Interactive effects of chronic stress and a high-sucrose diet on nonalcoholic fatty liver in young adult male rats. Stress 20 608-617. (https://doi.org/10.1080/10 253890.2017.1381840)

Dahm CH, Minagawa J \& Jellinek M 1977 Effects of progesterone on some enzymes of fat and carbohydrate metabolism in rat liver. American Journal of Obstetrics and Gynecology 129 130-132. (https:// doi.org/10.1016/0002-9378(77)90732-3)

Ducharme N, Banks WA, Morley JE, Robinson SM, Niehoff ML, Mattern C \& Farr SA 2010 Brain distribution and behavioral effects of progesterone and pregnenolone after intranasal or intravenous administration. European Journal of Pharmacology 641 128-134. (https://doi.org/10.1016/j.ejphar.2010.05.033)

Enos RT, Velázquez KT \& Murphy EA 2014 Insight into the impact of dietary saturated fat on tissue-specific cellular processes underlying obesity-related diseases. Journal of Nutritional Biochemistry 25 600-612. (https://doi.org/10.1016/j.jnutbio.2014.01.011)

Enos RT, Velázquez KT, McClellan JL, Cranford TL, Walla MD \& Murphy EA 2015 Lowering the dietary omega-6: omega-3 does not hinder nonalcoholic fatty-liver disease development in a murine model. Nutrition Research 35 449-459. (https://doi.org/10.1016/j. nutres.2015.04.003)

Enos RT, Velázquez KT, Carson MS, McClellan JL, Nagarkatti P, Nagarkatti M, Davis JM \& Murphy EA 2016 A low dose of dietary quercetin fails to protect against the development of an obese phenotype in mice. PLOS ONE 11 e0167979. (https://doi.org/10.1371/ journal.pone.0167979)

Floresco SB 2013 Prefrontal dopamine and behavioral flexibility: shifting from an 'inverted-U' toward a family of functions. Frontiers in Neuroscience 7 62. (https://doi.org/10.3389/fnins.2013.00062)

Floresco SB, Tse MTL \& Ghods-Sharifi S 2008 Dopaminergic and glutamatergic regulation of effort- and delay-based decision making. Neuropsychopharmacology 33 1966-1979. (https://doi.org/10.1038/ sj.npp.1301565)
Friberg E, Wallin A \& Wolk A 2011 Sucrose, high-sugar foods, and risk of endometrial cancer - a population-based cohort study. Cancer Epidemiology, Biomarkers and Prevention 20 1831-1837. (https://doi. org/10.1158/1055-9965.EPI-11-0402)

Gaysinskaya VA, Karatayev O, Shuluk J \& Leibowitz SF 2011 Hyperphagia induced by sucrose: relation to circulating and CSF glucose and corticosterone and orexigenic peptides in the arcuate nucleus. Pharmacology, Biochemistry, and Behavior 97 521-530. (https://doi. org/10.1016/j.pbb.2010.10.008)

Hart RP, Coover GD, Shnerson A \& Smotherman WP 1980 Plasma corticosterone elevations in rats in response to consumption of concentrated sugar solutions. Journal of Comparative and Physiological Psychology 94 337-345. (https://doi.org/10.1037/h0077662)

Heimovics SA, Prior NH, Maddison CJ \& Soma KK 2012 Rapid and widespread effects of $17 \beta$-estradiol on intracellular signaling in the male songbird brain: a seasonal comparison. Endocrinology 153 1364-1376. (https://doi.org/10.1210/en.2011-1525)

Hojo Y, Higo S, Ishii H, Ooishi Y, Mukai H, Murakami G, Kominami T, Kimoto T, Honma S, Poirier D, et al. 2009 Comparison between hippocampus-synthesized and circulation-derived sex steroids in the hippocampus. Endocrinology 150 5106-5112. (https://doi. org/10.1210/en.2009-0305)

Ikemoto S 2007 Dopamine reward circuitry: two projection systems from the ventral midbrain to the nucleus accumbens-olfactory tubercle complex. Brain Research Reviews 56 27-78. (https://doi.org/10.1016/j. brainresrev.2007.05.004)

Johnson RJ, Perez-Pozo SE, Sautin YY, Manitius J, Sanchez-Lozada LG, Feig DI, Shafiu M, Segal M, Glassock RJ, Shimada M, et al. 2009 Hypothesis: could excessive fructose intake and uric acid cause type 2 diabetes? Endocrine Reviews 30 96-116. (https://doi.org/10.1210/ er.2008-0033)

Keer SE \& Stern JM 1999 Dopamine receptor blockade in the nucleus accumbens inhibits maternal retrieval and licking, but enhances nursing behavior in lactating rats. Physiology and Behavior 67 659-669. (https://doi.org/10.1016/S0031-9384(99)00116-X)

Kendig MD, Rooney KB, Corbit LH \& Boakes RA 2014 Persisting adiposity following chronic consumption of $10 \%$ sucrose solution: strain differences and behavioural effects. Physiology and Behavior 130 54-65. (https://doi.org/10.1016/j.physbeh.2014.03.021)

Kimoto T, Ishii H, Higo S, Hojo Y \& Kawato S 2010 Semicomprehensive analysis of the postnatal age-related changes in the mRNA expression of sex steroidogenic enzymes and sex steroid receptors in the male rat hippocampus. Endocrinology 151 5795-5806. (https://doi. org/10.1210/en.2010-0581)

Kjaergaard M, Nilsson C, Rosendal A, Nielsen MO \& Raun K 2014 Maternal chocolate and sucrose soft drink intake induces hepatic steatosis in rat offspring associated with altered lipid gene expression profile. Acta Physiologica 210 142-153. (https://doi.org/10.1111/apha.12138)

Kleiner DE, Brunt EM, Van Natta M, Behling C, Contos MJ, Cummings OW, Ferrell LD, Liu YC, Torbenson MS, Unalp-Arida A, et al. 2005 Design and validation of a histological scoring system for nonalcoholic fatty liver disease. Hepatology 41 1313-1321. (https:// doi.org/10.1002/hep.20701)

Kovacs CS 2016 Maternal mineral and bone metabolism during pregnancy, lactation, and post-weaning recovery. Physiological Reviews 96 449-547. (https://doi.org/10.1152/physrev.00027.2015)

Kuo T, McQueen A, Chen TC \& Wang JC 2015 Regulation of glucose homeostasis by glucocorticoids. Advances in Experimental Medicine and Biology 872 99-126. (https://doi.org/10.1007/978-1-4939-2895-8_5)

la Fleur SE 2006 The effects of glucocorticoids on feeding behavior in rats. Physiology and Behavior 89 110-114. (https://doi.org/10.1016/j. physbeh.2006.01.028)

Lesser EN, Arroyo-Ramirez A, Mi SJ \& Robinson MJF 2017 The impact of a junk-food diet during development on 'wanting' and 'liking'. Behavioural Brain Research 317 163-178. (https://doi.org/10.1016/j. bbr.2016.09.041) 
Lomba A, Milagro FI, García-Díaz DF, Campión J, Marzo F \& Martínez JA 2009 A high-sucrose isocaloric pair-fed model induces obesity and impairs NDUFB6 gene function in rat adipose tissue. Journal of Nutrigenetics and Nutrigenomics 2 267-272. (https://doi. org/10.1159/000308465)

Maniam J, Antoniadis CP, Youngson NA, Sinha JK \& Morris MJ 2015 Sugar consumption produces effects similar to early life stress exposure on hippocampal markers of neurogenesis and stress response. Frontiers in Molecular Neuroscience 8 86. (https://doi.org/10.3389/fnmol.2015.00086)

Matkowskyj KA, Schonfeld D \& Benya RV 2000 Quantitative immunohistochemistry by measuring cumulative signal strength using commercially available software Photoshop and MATLAB. Journal of Histochemistry and Cytochemistry 48 303-312. (https://doi. org/10.1177/002215540004800216)

McMahon M, Gerich J \& Rizza R 1988 Effects of glucocorticoids on carbohydrate metabolism. Diabetes/Metabolism Reviews 4 17-30. (https://doi.org/10.1002/dmr.5610040105)

Mermelstein PG \& Becker JB 1995 Increased extracellular dopamine in the nucleus accumbens and striatum of the female rat during paced copulatory behavior. Behavioral Neuroscience 109 354-365. (https:// doi.org/10.1037//0735-7044.109.2.354)

Michelotti GA, Machado MV. \& Diehl AM 2013 NAFLD, NASH and liver cancer. Nature Reviews: Gastroenterology and Hepatology 10 656-665. (https://doi.org/10.1038/nrgastro.2013.183)

Mizuno G, Munetsuna E, Yamada H, Ando Y, Yamazaki M, Murase Y, Kondo K, Ishikawa H, Teradaira R, Suzuki K, et al. 2017 Fructose intake during gestation and lactation differentially affects the expression of hippocampal neurosteroidogenic enzymes in rat offspring. Endocrine Research 42 71-77. (https://doi.org/10.1080/0743 5800.2016.1182186)

Mohr MA, Wong AM, Tomm RJ, Soma KK \& Micevych PE 2019 Pubertal development of estradiol-induced hypothalamic progesterone synthesis. Hormones and Behavior 111 110-113. (https://doi. org/10.1016/j.yhbeh.2018.12.007)

Mosedale DE, Metcalfe JC \& Grainger DJ 1996 Optimization of immunofluorescence methods by quantitative image analysis. Journal of Histochemistry and Cytochemistry 44 1043-1050. (https://doi. org/10.1177/44.9.8773570)

Muschamp JW, Nemeth CL, Robison AJ, Nestler EJ \& Carlezon WA 2012 $\Delta$ FosB enhances the rewarding effects of cocaine while reducing the pro-depressive effects of the kappa-opioid receptor agonist U50488. Biological Psychiatry 71 44-50. (https://doi.org/10.1016/j. biopsych.2011.08.011)

Newens KJ \& Walton J 2016 A review of sugar consumption from nationally representative dietary surveys across the world. Journal of Human Nutrition and Dietetics 29 225-240. (https://doi.org/10.1111/ jhn.12338)

Ohashi K, Ando Y, Munetsuna E, Yamada H, Yamazaki M, Nagura A, Taromaru N, Ishikawa H, Suzuki K \& Teradaira R 2015 Maternal fructose consumption alters messenger RNA expression of hippocampal StAR, PBR, P450(11 $\beta), 11 \beta$-HSD, and 17 $\beta$-HSD in rat offspring. Nutrition Research 35 259-264. (https://doi.org/10.1016/j. nutres.2014.11.001)

Oliveira LSC, Santos DA, Barbosa-da-Silva S, Mandarim-de-Lacerda CA \& Aguila MB 2014 The inflammatory profile and liver damage of a sucrose-rich diet in mice. Journal of Nutritional Biochemistry $\mathbf{2 5}$ 193-200. (https://doi.org/10.1016/j.jnutbio.2013.10.006)

Paxinos G \& Watson C 2007 The rat brain in stereotaxic coordinates. 6th edn. Cambridge, MA, USA: Academic Press.

Pecoraro N, Reyes F, Gomez F, Bhargava A \& Dallman MF 2004 Chronic stress promotes palatable feeding, which reduces signs of stress: feedforward and feedback effects of chronic stress. Endocrinology 145 3754-3762. (https://doi.org/10.1210/en.2004-0305)

Pinheiro J, Bates D, Debroy S, Sarkar D \& R Core Team 2019 nlme: linear and nonlinear mixed effects models. R package version 3.1-141. (available at: https://CRAN.R-project.org/package=nlme)
Rada P, Avena NM \& Hoebel BG 2005 Daily bingeing on sugar repeatedly releases dopamine in the accumbens shell. Neuroscience 134 737-744. (https://doi.org/10.1016/j.neuroscience.2005.04.043)

Rafacho A, Ortsäter H, Nadal A \& Quesada I 2014 Glucocorticoid treatment and endocrine pancreas function: implications for glucose homeostasis, insulin resistance and diabetes. Journal of Endocrinology 223 R49-R62. (https://doi.org/10.1530/JOE-14-0373)

Reichelt AC, Abbott KN, Fred Westbrook RF \& Morris MJ 2016 Differential motivational profiles following adolescent sucrose access in male and female rats. Physiology and Behavior 157 13-19. (https:// doi.org/10.1016/j.physbeh.2016.01.038)

Robison AJ \& Nestler EJ 2011 Transcriptional and epigenetic mechanisms of addiction. Nature Reviews: Neuroscience 12 623-637. (https://doi. org/10.1038/nrn3111)

Ruff JS, Suchy AK, Hugentobler SA, Sosa MM, Schwartz BL, Morrison LC, Gieng SH, Shigenaga MK \& Potts WK 2013 Human-relevant levels of added sugar consumption increase female mortality and lower male fitness in mice. Nature Communications 4 2245. (https://doi. org/10.1038/ncomms3245)

Saben JL, Asghar ZA, Rhee JS, Drury A, Scheaffer S \& Moley KH 2016 Excess maternal fructose consumption increases fetal loss and impairs endometrial decidualization in mice. Endocrinology 157 956-968. (https://doi.org/10.1210/en.2015-1618)

Schindelin J, Arganda-Carreras I, Frise E, Kaynig V, Longair M, Pietzsch T, Preibisch S, Rueden C, Saalfeld S, Schmid B, et al. 2012 Fiji: an open-source platform for biological-image analysis. Nature Methods 9 676-682. (https://doi.org/10.1038/nmeth.2019)

Schmidt KL \& Soma KK 2008 Cortisol and corticosterone in the songbird immune and nervous systems: local vs. systemic levels during development. American Journal of Physiology: Regulatory, Integrative and Comparative Physiology 295 R103-R110. (https://doi.org/10.1152/ ajpregu.00002.2008)

Sharpe MJ, Clemens KJ, Morris MJ \& Westbrook RF 2016 Daily exposure to sucrose impairs subsequent learning about food cues: a role for alterations in ghrelin signalling and dopamine D2 receptors. Neuropsychopharmacology 41 1357-1365. (https://doi.org/10.1038/ npp.2015.287)

Stafeev IS, Vorotnikov AV, Ratner EI, Menshikov MY \& Parfyonova YV 2017 Latent inflammation and insulin resistance in adipose tissue. International Journal of Endocrinology 2017 5076732. (https://doi. $\operatorname{org} / 10.1155 / 2017 / 5076732)$

Steingrimsdottir L, Greenwood MRC \& Brasel JA 1980 Effect of pregnancy, lactation and a high-fat diet on adipose tissue in Osborne-Mendel Rats. Journal of Nutrition 110 600-609. (https://doi. org/10.1093/jn/110.4.600)

Tappy L \& Lê KA 2010 Metabolic effects of fructose and the worldwide increase in obesity. Physiological Reviews 90 23-46. (https://doi. org/10.1152/physrev.00019.2009)

Taves MD, Ma C, Heimovics SA, Saldanha CJ \& Soma KK 2011 Measurement of steroid concentrations in brain tissue: methodological considerations. Frontiers in Endocrinology 239. (https://doi.org/10.3389/fendo.2011.00039)

Taves MD, Hamden JE \& Soma KK 2017 Local glucocorticoid production in lymphoid organs of mice and birds: functions in lymphocyte development. Hormones and Behavior 88 4-14. (https://doi. org/10.1016/j.yhbeh.2016.10.022)

Tirosh A, Garg R \& Adler GK 2010 Mineralocorticoid receptor antagonists and the metabolic syndrome. Current Hypertension Reports 12 252-257. (https://doi.org/10.1007/s11906-010-0126-2)

Tobiansky DJ, Roma PG, Hattori T, Will RG, Nutsch VL \& Dominguez JM 2013 The medial preoptic area modulates cocaine-induced activity in female rats. Behavioral Neuroscience 127 293-302. (https://doi. org/10.1037/a0031949)

Tobiansky DJ, Will RG, Lominac KD, Turner JM, Hattori T, Krishnan K, Martz JR, Nutsch VL \& Dominguez JM 2016 Estradiol in the preoptic area regulates the dopaminergic response to cocaine in the nucleus https://joe.bioscientifica.com

https://doi.org/10.1530/JOE-19-0386
(C) 2020 Society for Endocrinology Published by Bioscientifica Ltd. Printed in Great Britain 
accumbens. Neuropsychopharmacology 41 1897-1906. (https://doi. org/10.1038/npp.2015.360)

Tobiansky DJ, Wallin-Miller KG, Floresco SB, Wood RI \& Soma KK $2018 a$ Androgen regulation of the mesocorticolimbic system and executive function. Frontiers in Endocrinology 9 279. (https://doi.org/10.3389/ fendo.2018.00279)

Tobiansky DJ, Korol AM, Ma C, Hamden JE, Jalabert C, Tomm RJ \& Soma KK $2018 b$ Testosterone and corticosterone in the mesocorticolimbic system of male rats: effects of gonadectomy and caloric restriction. Endocrinology 159 450-464. (https://doi org/10.1210/en.2017-00704)

Tomm RJ, Tse MT, Tobiansky DJ, Schweitzer HR, Soma KK \& Floresco SB 2018 Effects of aging on executive functioning and mesocorticolimbic dopamine markers in male Fischer $344 \times$ brown Norway rats. Neurobiology of Aging 72 134-146. (https://doi.org/10.1016/j. neurobiolaging.2018.08.020)

Vasiljević A, Bursać B, Djordjevic A, Milutinović DV, Nikolić M, Matić G \& Veličković N 2014 Hepatic inflammation induced by high-fructose diet is associated with altered 11ßHSD1 expression in the liver of Wistar rats. European Journal of Nutrition 53 1393-1402. (https://doi org/10.1007/s00394-013-0641-4)
Wei R, Wang J, Su M, Jia E, Chen S, Chen T \& Ni Y 2018 Missing value imputation approach for mass spectrometry-based metabolomics data. Scientific Reports 8 663. (https://doi.org/10.1038/s41598-01719120-0)

Welsh JA, Sharma AJ, Grellinger L \& Vos MB 2011 Consumption of added sugars is decreasing in the United States. American Journal of Clinical Nutrition 94 726-734. (https://doi.org/10.3945/ajcn.111.018366)

Wild P, Rupp N, Buhmann J, Schüffler P, Fuchs T \& Ong C 2013 TMARKER: a free software toolkit for histopathological cell counting and staining estimation. Journal of Pathology Informatics 4 2. (https:// doi.org/10.4103/2153-3539.109804)

World Health Organization 2015 Guideline: Sugars intake for adults and children. Geneva, Switzerland: World Health Organisation. (available at: https://www.who.int/nutrition/publications/guidelines/sugars intake/en/)

Zhang Y, Crofton EJ, Li D, Lobo MK, Fan X, Nestler EJ \& Green TA 2014 Overexpression of DeltaFosB in nucleus accumbens mimics the protective addiction phenotype, but not the protective depression phenotype of environmental enrichment. Frontiers in Behavioral Neuroscience 8 297. (https://doi.org/10.3389/ fnbeh.2014.00297)

Received in final form 5 February 2020

Accepted 21 February 2020
(C) 2020 Society for Endocrinology Published by Bioscientifica Ltd. 